\title{
Über das Querdenken
}

\section{Eberhard Wolff}

Prof. Dr. rer. soc., Redaktor Kultur, Geschichte, Gesellschaft

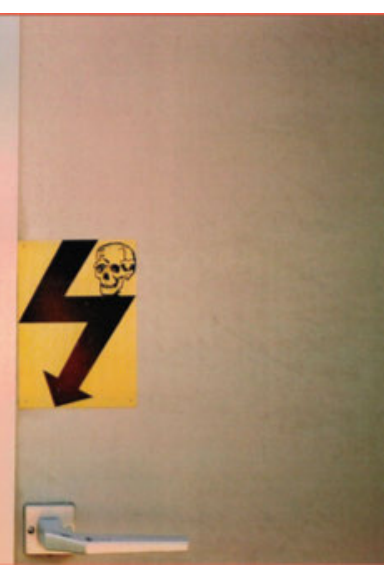

eberhard.wolff[at]saez.ch
«Würde man die Türe öffnen, und der Türgriff lässt erwarten, dass die Türe nach innen sich öffnet, würde man diese Türe öffnen (vorausgesetzt, sie liesse sich öffnen), träte man ein in das Reich der Toten. Der neben dem schwarzen Stromblitz abgebildete Schädel duldet keine andere Interpretation. So kalt, prosaisch, hat man sich den Eingang in die Unterwelt, das Totenreich, vorzustellen. Denn dort, ohne Zweifel, herrscht der Tod. Etwas enttäuschend dieser Eingang, trotz aller Verwunderung über die allzeit, allüberall, allumfassende, vorherrschende Dominanz der Meister der Tode. Und dass diese seit Tausenden von Jahren kein anderes Firmenzeichen als ihre Schädel zu nutzen wissen, passt zur einfältigen Türe. Und doch: Die Vorstellung, dass, im Extremsten, nur wenige Millimeter uns trennen von der anderen Seite, vom Da ins Nichts, ist verführerisch.»

Wer diese Zeitschrift in den letzten Jahren aufmerksam gelesen hat, der wird schnell erraten, welcher Autor hier das abgebildete Foto erklärt: Enrico Danieli. Seit vielen Jahren hinterlässt der schriftstellernde Arzt aus dem Tessin in diesem Blatt seine ganz speziellen Spuren. Kürzlich etwa seine lustigen Jugend-Verirrungen mit der Frau Doktor Mann oder die deprimierende Blossstellung als «Lithium»-Patient.

In einem eben erschienenen Band [1] hat er sich dem Phänomen «Schilder» angenommen. Danieli hat sie in den letzten Jahren auf seinen Touren mit dem privaten Fotoapparat aufgelesen. Wegweiser, Hinweis-, Warnoder Verbotsschilder. Und 66 davon hat er mit sprachlichen "Pirouetten" versehen. Aus einer von ihnen stammt der obige Eingang ins Jenseits.

Natürlich sind auch solche selbstgebastelten Schilder darunter, deren unbeholfener oder ungewöhnlicher Text unfreiwillige Komik verbreitet: «Einwurf für Kleintiere (zur Verbrennung)» oder «Tierkörper. Ganze Kuhköpfe und andere Schlachtabfälle zur Verbrennung». Danieli bleibt dort nicht stehen. Eines seiner Markenzeichen ist das systematische Missverstehen. Da wird aus der unscheinbaren Tür zum HochspannungsSchaltraum der Eingang in das Reich der Toten. Ein unglücklich nach oben weisender Pfeil auf einem «Privat»-Schild ist für Danieli der Beweis, dass auch der Himmel im Besitz von «Himmelbesitzern» ist. Er meint es nicht böse. Es ist für ihn der Weg, auf dem sich ganz neue Denk-Dimensionen auftun.
Der Autor hat dabei ein offensichtliches Faible für Wegweiser zur nächsten Toilette. Ganz speziell solche, die sich gleichberechtigt an Wegweiser zu anderen Zielen anhängen: Hier geht's zur Naturschönheit der Gletschertöpfe - und zum WC. Zwei Zwillings-Wegweiser auf grünem Grund. Wenn nun aber grüne Wegweiser auf Naturschutzgebiete hinweisen, führt das grüne WC-Schild dann zu einer Naturtoilette? Einem Naturtopf?

Hier geht's zur Kirche - und zum WC. Diesmal auf blauem Grund. Die Kirche zur Erleichterung der Seelenlast. Das WC zur Erleichterung der Blasenlast. Und plötzlich tun sich viele Gemeinsamkeiten zwischen dem stillen Örtchen und dem Raum der Stille auf.

Szenenwechsel zu einer Abdankungshalle. Ein Anschrieb auf einer Tür: Hier geht's zu den Aufbahrungsräumen - und natürlich auch zum WC. "Verbindend wäre wohl das Ausgeschiedene, die Einen aus der Gesellschaft, das Andere der Rest vom Körper.»

Das Querdenken hat etwas Anarchisches. Und es führt an die Grenzen des Lebens, an denen Danieli ständig arbeitet, mit ihnen kokettiert. Das Ertrinken zieht sich wie ein roter Faden durch sein «Divertimento a bassa voce», begleitet vom Schlachten, Vergiften, Ermorden, von der Hölle, dem Sterben, dem Ende. Ein Foto zeigt eine Boje, ein Stück vom Strand entfernt im Meer dümpelnd. Sie warnt unbedachte Schwimmer mit der Aufschrift «Reicht es auch zurück?». «Reicht es nicht zurück», trotzt Danieli, "so reicht es doch weiter, immer weiter."

Ja, der Gedanke mag verführerisch sein, die Tür mit dem Totenkopf und dem Stromblitz drauf zu öffnen und hineinzusehen. Trotzdem würde ich nicht nur dem Kollegen Danieli davon abraten, es wirklich zu tun. Es könnte sich herausstellen, dass sich hinter dem Eingang ins Reich der Toten überhaupt nichts befindet. Allenfalls ein langweiliger HochspannungsSchaltraum.

\section{Bildnachweis}

Foto: Enrico Danieli

\section{Literatur}

1 Danieli E. 66 Plaquetten mit Pirouetten. Bagatellen zu Pictogrammen, Photogrammen, Paragrammen und ihren Melodrammen. Literareon, 166 S., € 29, Fr. 39. ISBN 978-3-8316-2024-1. 